\title{
Knowledge Relation Of Pregnant Women About Dangers Of Pregnancy With Compliance Performing Anc Visitation In Work Area Of Basarang Commutity Health Center Of Kapuas Regency
}

\author{
Dwi Rahmawati ${ }^{1}$, Desilestia Dwi Salmarini ${ }^{2}$ \\ \{dwislamet21@gmail.com\} \\ Departmen of Midwifery, Faculty of Health Universitas Sari Mulia Banjarmasi, Indonesia ${ }^{1,2}$
}

\begin{abstract}
The high maternal and infant mortality rates are caused by the low level of maternal knowledge and the frequency of irregular ANC examinations. Basarang Puskesmas data for January-June 2017, ANC service coverage has decreased namely K1 $102(50.73 \%)$ K4 83 (47.29\%). Coverage K1 to K4 has not yet reached the national target Objective: To find out the relationship between Pregnant Mother's Knowledge of Pregnancy Hazards and Compliance with Antenatal Care Visits in the Work Area of the Basarang Health Center Method: Analytic with cross sectional approach. Chi Square data analysis technique Results: pregnancy danger signs with insufficient knowledge of 19 respondents (42.2\%), only $10(22.2 \%)$ good as many as 16 (35.6\%). Compliance with ANC visits to non-compliant pregnant women as many as 24 (53.3\%)compliant 21 (46.7\%)obtained a $\mathrm{P}$ value of 0.018 Conclusion: There is a correlation between the knowledge of pregnant women about the danger signs of pregnancy with the compliance of antenatal care visits (ANC) in the work area of the Basarang Puskesmas.
\end{abstract}

Keywords: Antenatal care (ANC) visit, Knowledge, Sign of danger of pregnancy

\section{Introduction}

Pregnancy is a physiological or natural thing. However, each pregnancy has the potential to be pathological so that midwives must be able to carry out promotive and preventive efforts to anticipate the occurrence of complications and abnormalities in pregnancy. One factor that influences the high maternal mortality rate is the attitude and behavior of the mother herself during pregnancy and is supported by the mother's knowledge of her pregnancy [1]. The maternal mortality rate (MMR) and infant mortality rate (IMR) in the world are still relatively high, according to data from the World Health Organization (WHO) in 2013, there are around 800 mothers in the world die every day due to complications of pregnancy and childbirth. The main causes of maternal death include low resources, bleeding, hypertension, infections, and other comorbidities suffered by mothers before pregnancy. 
Based on the 2016 SDGs Target, Indonesia is one of the Failed Countries in reducing Maternal Mortality Rate (MMR). Efforts and hard work have been carried out in fact the MMR is still quite high, reaching 359 per 100,000 live births. The target set by the SDGs in the next 1.5 years regarding MMR is the reduction in MMR to 70 per 100,000 live births. In Indonesia alone the MMR is still relatively high when compared with neighboring countries, according to the 2012 Indonesian demographic and health survey (IDHS) the MMR related to pregnancy, childbirth, and childbirth is 359 per 100,000 live births (KH). This figure is not in accordance with the target SDGs of 102 / 100,000 KH [2]. Antenatal Care (ANC) as one of the early prevention efforts from pregnancy risk factors. According to the World Health Organization (WHO) Antenatal care to detect early occurrence of high risk of pregnancy and childbirth can also reduce maternal mortality and monitor the state of the fetus. Ideally, if every pregnant woman wants to have her pregnancy examined, the aim is to detect any abnormalities that may or might occur in the pregnancy quickly, and can be treated immediately before the adverse effect on the pregnancy by conducting antenatal care checks. Antenatal care is the most important component of maternal health services to reduce maternal and infant mortality [2].

The high rate of maternal and infant mortality is partly due to the low level of knowledge of the mother and the frequency of irregular ANC examinations. The regularity of ANC can be addressed through the frequency of visits, it turns out this is a problem because not all pregnant women check their pregnancy routinely, especially pregnant women so that abnormalities that arise in pregnancy can not be detected as early as possible. There are several factors that cause why pregnant women are less motivated to conduct regular and timely ANC visits, among others: mother's knowledge, low economic level, lack of husband and family support [3].

According to the Profile of the Central Kalimantan Provincial Health Service in 2015, the number of maternal deaths in the province of Central Kalimantan AKI of Central Kalimantan still follows national figures, which are the results of the 2007 Indonesian Demographic Health Survey (IDHS) of 228 per 100,000 live births. with pregnancy, childbirth, and childbirth) of 359 per 100,000 live births based on the 2012 Indonesian Demographic and Health Survey (SDKI). The number of maternal deaths reported in Central Kalimantan Province in 2015 was 80 cases. The number is far less when compared to the number of maternal death cases in 2014 of 101 cases, but these cases are still categorized high. Then Coverage of visits of pregnant women In 2015 K4 service coverage of $82.8 \%$ there was a decrease when compared to the achievements in 2014 amounted to $86.5 \%$. In general, almost all municipalities have not achieved the target of $95 \%$ [4].

Government program policies that ANC visits should be done four times during pregnancy, namely once in the first trimester, once in the second trimester and twice in the third trimester while the visit of pregnant women consists of $\mathrm{k} 1$ visit and $\mathrm{k} 4$ visit (Karwati, et al, 2011) [ 5]. Menurut data Dinas Kesehatan Kabupaten kapuas tahun 2016, The data obtained that visits K1 and K4 decreased. In 2016 the highest visits of all puskesmas were: Melati K1 $715(95.21 \%)$ and K4 693 (92.28\%), Anjir K1 489 (90.33\%) and K4 412 (76.10\%), and 412 K4 (76.10\%) Puskesmas, 412 (76.10\%), Most health centers were K1 418 (84.51\%) and K4 378 (76.42\%), Puskesmas Basarang K1 427 (83.2\%) and K4 313 (75.5\%) [6]Based on reports on the results of the activities of the $\mathrm{MCH}$ Basarang health center program in 2017 from January to June, the scope of ANC services has decreased visits namely K1 102 $(50.73 \%)$ and K4 $83(47.29 \%)$. Coverage of K1 to K4 has not yet reached the national target. In the implementation of antenatal care, mothers will be more obedient if they get support from the family. In this case support from husband, family and community greatly influences 
the successful implementation of ANC. Factors that influence the non-compliance of pregnant women in conducting ANC visits include due to lack of family knowledge and support [6].

Based on a preliminary study conducted by researchers in August 2017 with question and answer techniques for 10 pregnant women regarding knowledge of danger signs of pregnancy, obtained from 10 pregnant women who did not make ANC visits, 7 of whom did not recognize the danger signs of pregnancy, only 3 pregnant women can mention various danger signs of pregnancy but they still do not visit the ANC because they do not complain anything about the pregnancy [7].

\section{Research Methode}

This research is an analytic with cross sectional approach. The population in this study were all Trimester III pregnant women who participated in pregnant women classes in the working area of the basarang puskesmas, amounting to 83 people. Sampling with Accidental Sampling Technique obtained 43 people. Chi Square data analysis technique

\section{Result and Discussion}

\subsection{Univariate Analysisa.}

a Knowledge of danger signs of pregnancy

Tabel 1. Knowledge of danger signs of pregnancy

\begin{tabular}{ccc}
\hline Knowledge & $\mathrm{F}$ & $\%$ \\
\hline Well & 16 & 35.6 \\
\hline Enough & 11 & 24.4 \\
\hline Less & 18 & 40.0 \\
\hline amount & 45 & 100 \\
\hline
\end{tabular}

From Table 1, knowledge about the danger signs of pregnancy is good as 16 (35.6\%), quite as much as $11 \mathrm{r}(24.4 \%)$ and less as much as $18(40 \%)$.

b Compliance Antenatal Care visits to pregnant women

Table 2 Distribution of frequency of compliance with Antenatal Care visits in pregnant women TM 3

\begin{tabular}{ccc}
\hline Obedience & F & $\%$ \\
\hline Not obey & 24 & 53.3 \\
\hline Obedient & 21 & 46.7 \\
\hline amount & 45 & 100 \\
\hline
\end{tabular}


From Table 2, there were $24(53.3 \%)$ and $21(46.7 \%)$ non-compliant visits to the ANC.

\subsection{Analisa Bivariat}

Table 3 Relationship Knowledge about Pregnancy Hazard Signs with Compliance Antenatal Care (ANC) Visit to Pregnant Women

\begin{tabular}{ccccccc}
\hline \multirow{2}{*}{ Pengetahuan } & \multicolumn{4}{c}{ Kepatuhan } & \multirow{2}{*}{ Total } \\
\cline { 2 - 6 } & \multicolumn{2}{c}{ Tidak } & \multicolumn{2}{c}{ Patuh } & & \\
\cline { 2 - 6 } & $\mathrm{f}$ & $\%$ & $\mathrm{f}$ & $\%$ & $\mathrm{n}$ & $\%$ \\
\hline Baik & 4 & 8,9 & 12 & 6,7 & 16 & 35,6 \\
\hline Cukup & 8 & 17,8 & 3 & 6,7 & 11 & 24,4 \\
\hline Kurang & 12 & 26,7 & 6 & 13,3 & 18 & 40 \\
\hline Jumlah & 24 & 53,3 & 21 & 46,7 & 45 & 100 \\
\hline
\end{tabular}

Based on Table 3, there was $12(28.9 \%)$ compliant good knowledge of ANC visits, $8(17.8 \%)$ average non-compliant visits and $12(26.7 \%)$ obedient knowledge ). Chi-Square statistical test if $\mathrm{P}$ value $<0.05$ and the relationship is said not significant if $\mathrm{P}$ value $>0.05$ obtained 0.017 , which means $\mathrm{P}$ value $<0.05$ means there is a relationship between knowledge of pregnant women about the danger signs of pregnancy with compliance with antenatal care visits (ANC) in the work area of the Basarang Puskesmas.

The statistical test used was chi square where the test in this study was in accordance with the test requirements ie the number of samples $>40$ and none with the reality frequency value or also called the actual count (Fo) of 0 (zero).

\section{Discussion}

1. Knowledge of danger signs of pregnancy

From the research results obtained knowledge about danger signs of pregnancy from 45 pregnant women have less knowledge as much as 18 (40\%). According to the authors of the results of research that have been done there are still respondents who have less knowledge about the danger signs of pregnancy because the majority of pregnant women with basic education (SD-SMP) 73.3\% where the level of education greatly affects the level of knowledge of a person whereas in terms of age can be in the most studies of pregnant women aged 20-35 years which should indicate a person's level of maturity is more mature to think and explore information. The majority of pregnant women also work as housewives (IRT) as much as $71.1 \%$ so that mothers have reason not to participate in counseling activities carried out by puskesmas with reasons being busy with homework, lazy to leave home, look after the house, lack of family support so pregnant women lack information outside of the danger signals. There are also many pregnant women who have never had children, which greatly affects their knowledge. Because the number of children based on experience as a source that can increase knowledge because it can repeat the knowledge gained previously. 
This shows about mothers who do not want to know about the information provided and consider mothers to get information about the mother and fetus. Pregnant women do not check their pregnancies regularly, so they do not detect danger signs and complications that occur during pregnancy or during labor which will hamper the mother and fetus. Therefore, it is required that health workers in the area of the basarang health center need to do health promotion or health education for each pregnant woman specifically about the danger signs during the class of pregnant women as well as by visiting the home of pregnant women one by one so that they can visit their mother and fetus more. Thus in expecting pregnant women to have good knowledge about the danger signs of pregnancy.

This is consistent with the theory of Sukmadinata (2013) that education influences knowledge because one's level education will influence the response coming from outside. Educated people will think about the benefits they might get from the idea. But this is not in accordance with the theory of Prawirohadjo (2009) that mothers aged 20-35 years are expected to be able to solve problems faced calmly emotionally, the more age increases the better the percentage of knowledge because it is caused by access to information, insight, and mobility is still low and a person's level of maturity in thinking and working will also be better. The results of this study are supported by Sukmadinata's theory (2013).

Humans are social creatures, where in the lives of individuals one interacts with other individuals and can interact inwardly so as to be exposed to information. Through work and routine someone will interact with others and be exposed to information. According to Chapman's Theory (2009) that parity in pregnancy is an experience for mothers who can provide increased maternal knowledge. Experience can be a source of someone's knowledge in knowing or knowing something that has never been known before. Experience is a way to obtain the truth of knowledge by repeating the knowledge gained in solving problems faced by the past.

The results of this study are consistent with Elisa (2014) that most of the ages are 20-35 years. Age is one of the risk factors related to the quality of pregnancy or closely related to the physical readiness of the mother in reproduction. The low level of education affects the quality of health due to the lack of knowledge about danger signs of pregnancy. Women's economic activities can influence their access to material through income-generating work. Work is related to one's socioeconomic, the higher the socioeconomic level of a person will increase the level of knowledge.

Based on research conducted on 45 respondents using a questionnaire in the knowledge about the most danger signs of pregnancy is lacking. Lack of maternal knowledge is caused by many respondents answering wrongly to number 3 regarding danger signs of blood coming out of the woman's female area and problem number 6 regarding danger signs there is no fetal movement for 3 hours by $26(57.8 \%)$.

The results of this study are not in accordance with the research of Lusia Wahyu Beribe (2012) that more respondents know about vaginal bleeding in pregnancy. Knowledge held by pregnant women about vaginal bleeding is obtained through various processes. Not only from formal education but also non-formal education, one of which is through counseling. Counseling is one way for pregnant women to get information about pregnancy so that pregnant women can recognize the danger signs of vaginal bleeding in pregnancy. Pregnant women can also find out the cause of vaginal bleeding, the classification of treatment and prevention of vaginal bleeding. 
The results of this study are not in accordance with the research of Lusia Wahyu Beribe (2012) that more respondents who know about fetal movements are reduced. Knowledge of pregnant women about fetal movement is reduced at least can prevent fetal death in the womb. Pregnant women can feel the fetus's pain. If the mother feels less fetal movement, then the pregnant woman can be more vigilant because that might be a sign of gawatjanin so that the mother can immediately get her pregnancy checked by a health worker. But on the contrary, if a pregnant woman does not know about fetal movement is reduced, it might be considered that it is natural, so they do not know that it can cause fetal distress to lead to fetal death in the womb.

One of the knowledge that high risk pregnant women must know is knowledge about danger signs of pregnancy. Pregnancy danger signs are signs that indicate a danger that can occur during pregnancy or the antenatal period, which if not reported or not detected can cause maternal death. Pregnancy danger signs are signs that indicate a danger that can occur during pregnancy, which if not reported or not detected can cause maternal death (Asrinah, 2010).

Less important mother's knowledge answers a lot about danger signals about female mothers. Normal pregnancy is identical to amenorrhea and there is no vaginal bleeding, but many women also experience episodes of bleeding in the first trimester of pregnancy. Blood that comes out is usually fresh (bright red) and dark colored (blackish brown). Bleeding that occurs is very mild, but persists for several days or suddenly comes out in large numbers. Vaginal bleeding in young pregnancies is suspended by abortion, ectopic pregnancy and hydatidiform mole (Varney, 2007).

Lack of maternal knowledge is caused by many respondents answering incorrectly about danger signs regarding no fetal movement for 3 hours. Normally mothers begin to feel the movements of their fetus during the 5th or 6th month, some mothers can feel the movements of their babies earlier. When the baby sleeps, his movements will weaken, the baby's movements will be easily felt if the mother lies down or rests and if the mother eats and drinks well. Usually the signs and symptoms are baby's movements less than 3 times in a 3 hour period (Asrinah et al, 2010).

This study is not in accordance with Elisa's (2014) study that most of the mother's knowledge is sufficient about the danger signs of pregnancy. According to Azwar (2010) stated that knowledge is a habit, expertise or expertise, skills, understanding or understanding obtained from experience, training or through the learning process. This theory is supported by Sukmadinata (2013), one's knowledge is influenced by several factors, namely: education, mass media exposure, economy, social relations and experience. Someone who is more often exposed to mass media (TV, radio, magazines, pamphlets) will get more information than people who have never been exposed to media information.

Knowledge is a very important domain for the formation of one's actions. With increasing education and information obtained, it will increase knowledge and will lead to positive attitudes or behaviors. The factors that influence knowledge are age, education, work and parity.

\section{Compliance Antenatal Care visits to pregnant women}

From the results of the study of 45 mothers of maternal mortality, it was found that there were 24 non-adherent ANC visits (53.3\%) Non-compliance of mothers in ANC visits was due to lack of understanding of instructions (Pratitis, 2013). Good knowledge about the importance of antenatal care can encourage maternal awareness to 
be active in carrying out regular ANC visits so that the achievement of antenatal care goals (Siregar, 2011).

The results of this study are still the presence of pregnant women who are not compliant in ANC visits, showing that non-compliance is influenced by the level of knowledge of pregnant women who tend to be still lacking. Compliance of pregnant women is also influenced by the level of education of pregnant women, the majority of which are primary education and work as IRT. Low education causes low knowledge as well so that it affects the compliance of pregnant women in conducting ANC visits. It means that the better the knowledge of pregnant women is a danger sign of pregnancy, the more obedient it is to conduct ANC visits.

According to the author, pregnant women do not comply with ANC visits because they do not understand the benefits of ANC visits and the impact of not doing ANC visits. Another factor that causes the lack of interest of pregnant women to visit ANC is because they cannot routinely come every month for pregnant mothers' health associations because many of them have reasonable distance, there is no adequate means of transportation and lack of family support, especially the husband. So it is expected that health workers, especially midwives in the area of the basarang health center play more roles and provide support, health promotion and embracing pregnant women to have the willingness to visit ANC in the area of the Basarang health center.

The results of this study are consistent with Kusomo Bayu Hargo's research (2016) that the majority of antenatal care visit compliance is compliant with $60.6 \%$, while non-compliant is $39.4 \%$. These results state that the majority of mothers who have compliance with visits are good enough, this is comparable to the level of knowledge of respondents who are mostly categorized as good.

Compliance is the behavior of pregnant women in conducting antenatal care visits where mothers are classified as compliant if they make a minimum of 1 trimester pregnancy visits 1 , trimester 21 times and trimester 32 times. Pregnancy examination (antenatalcare) is a planned program of observation, education, and medical treatment for pregnant women, to obtain a safe and satisfying pregnancy and childbirth process (Marmi, 2011).

3 Relationship between knowledge of pregnant women about the danger signs of pregnancy with adherence to antenatal care visits (ANC)

From the results of research conducted on 45 pregnant women obtained good knowledge of compliant ANC visits as many as $12(28.9 \%)$, quite disobedient knowledge of ANC visit visits as many as 8 (17.8\%) and insufficient knowledge of as many as $12(26.7 \%)$. Chi-square statistical test if $\mathrm{P}$ value $<0.05$ and the relationship is said not significant if $\mathrm{P}$ value $>0.05$ obtained 0.017 which means $\mathrm{P}$ value $<0.05$ means there is a relationship between knowledge of pregnant women about the danger signs of pregnancy with compliance with antenatal care visits (ANC) in the work area of the Basarang Puskesmas.

This study is supported by Yanti (2012) that there is a significant relationship between knowledge of pregnant women about danger signs and complications of pregnancy with compliance with antenatal visits meaning that pregnant women who have higher levels of knowledge have better adherence than pregnant women who have higher levels of knowledge low while low knowledge has poor compliance compared to pregnant women who have high levels of knowledge. 
4 Knowledge is theoretically a predisposing factor for behavior, so knowledge about pregnancy danger signals can shape health behavior in the form of compliance with antenatal care. Respondents' knowledge about the high risk of pregnancy provides pregnant women with an understanding of the importance of antenatal care visits. The knowledge possessed by respondents includes information that increases respondents' confidence about the importance of antenatal care visits, as well as the knowledge they have is able to mobilize them to conduct antenatal care visits. Knowledge (knowledge) is an essential part of human knowledge. Human knowledge is obtained through its perception of stimuli using the senses, the results of perception in the form of information will be stored in the memory system to be processed and given meaning, then the information is used (retrieval) when needed. Thus, the higher the level of knowledge of respondents about the high risk of pregnancy will have an effect on increasing the awareness and willingness of respondents to make antenatal care visits.

\section{Conclusions}

There is a correlation between the knowledge of pregnant women about the danger signs of pregnancy with the compliance of antenatal care visits (ANC) in the work area of the Basarang Puskesmas.

\section{Acknowledgents}

I thank those who Jamhuri, SKM.,MAP, as a director have given permission and the opportunity to do research in the . Basarang Commutity Health Center Of Kapuas Regency

\section{References}

[1] Puspasari FD, et al.: Factors that affect the attitude of pregnant women in identifying signs of pregnancy danger in the village of Sokaraja Central Sokaraja District Banyumas. The FKIK Journal of the University of General Sudirman Purwokerto. 2008. Volume 3 (2008)

[2] E Elisha:: Age, education, employment and knowledge level Primigravida about the danger signs of pregnancy Iii Trimester in the Puskesmas area of Ungaran West Ungaran district of Semarang District. Nursing Care Journal 2 (2014)

[3] De Ministry of Health Republic of Indonesia.: Obstetrics service standards. Jakarta: Depkes RI (2007)

[4] Tika Febriani.: An overview of the knowledge and attitude of expectant mothers about the high risk pregnancy in Banjarmasin Pekauman Puskesmas. (KTI). Banjarmasin (2016)

[5] Dewi Ida Arini.: ANC's visit and compliance with the incidence of Anemia in pregnant women in Kertak Hanyar Health Center. SKRIPSI. Banjarmasin. STIKES Sari Mulia (2017) 
[6] Provincial Health Office of Central Kalimantan.: Provincial health profile of central Kalimantan. Palangkaraya: Provincial health Office of Central Kalimantan (2015)

[7] Kapuas District Health Office.: Scope of Antenatal Care service: The Health Office of Kapuas Regency (2016)

[8] Elverawati. The participation of pregnant women to Antenatal Care visits at the health center of Lung Bata, Banda Aceh in (2008)

[9] Lusia Wahyu Beribe.: Overview of pregnant women's knowledge about signs of pregnancy dangers in Puskesmas Plus Bara-Baraya year 2012. Thesis. Studied obstetrician Faculty of Health Sciences Alauddin State Islamic University of Makassar (2012)

[10] Rika Wulandari.: Knowledge level relations of pregnant mothers with the knowledge of pregnancy hazard signs in the III trimester at RB Harapan Bunda Surakarta. (KTI). Surakarta. The STIKES PKU Muhamadiyah Surakarta (2014)

[11] Varney,H.: Obstetrician Orphanage Edition 4. Jakarta: EGC (2007)

[12] Wiknjosastro, Hanifa.: Obstetrician Sciences. Jakarta: Yayasan Bina Pustaka (2010)

[13] Sulistyawati, A.: Obstetrics and gynaecology during pregnancy. Jakarta : Salemba Medika (2009)

[14] Marmi.: Obstetrics care at the Antenatal period, Yogyakarta; Pustaka pelajar (2011)

[15] Asrinah.: Obstetrics and gynaecology during pregnancy. Yogyakarta : Graha Ilmu (2010)

[16] Syafrudin dkk.: Community Obstetrics. Jakarta: ECG (2009)

[17] Azwar.: Human attitude: Theory and measurement. Yogyakarta: Pustaka Pelajar (2010)

[18] Susetya.: Statistics for analysis of research data. Bandung. Refika Aditama (2010)

[19] Sukmadinata, N.: Cornerstone of Psychology education. Bandung: PT Remaja Pusdakarya (2013) 